\title{
Quantitative transportation assessment in simulated curved canals after large apical preparations
}

\author{
Vânia Cristina Gomes Vieira', Felipe Gonçalves Belladonna², Erick Miranda Souza ${ }^{3}$, Gustavo De-Deus², Aline de \\ Almeida Neves ${ }^{4}$, Edson Jorge Lima Moreira', Emmanuel João Nogueira Leal Silva ${ }^{1}$ \\ 'Department of Endodontics, School of Dentistry, Grande Rio University (UNIGRANRIO), Duque de Caxias, RJ, Brazil \\ 2Department of Endodontics, Fluminense Federal University (UFF), Niterói, RJ, Brazil \\ ${ }^{3}$ Department of Restorative Dentistry II, Federal University of Maranhão (UFMA), São Luis, MA, Brazil \\ ${ }^{4}$ Department of Paediatric Dentistry, Rio de Janeiro Federal University (UFRJ), Rio de Janeiro, RJ, Brazil
}

\begin{abstract}
Aim: To evaluate the ability of rotary (ProTaper Universal [PTU] and ProTaper Next [PTN]), reciprocating (Reciproc [R] and WaveOne [WO]) and adaptive (Twisted File Adaptive [TFA]) systems in maintaining the original canal profile in straight and curved parts after apical preparations up to size 40. Methods: Resin blocks with simulated curved canals were randomly assigned to five groups: PTU, PTN, R, WO and TFA. Images were captured from each block before and after canal preparation $(n=10)$. Assessment of canal transportation was obtained for the straight and curved parts of the canal. ANOVA followed by Tukey's test was used $(\alpha=5 \%)$. Results: Transportation values were increased at the curved part $(P=.00)$. For both canal levels, TFA system induced the lowest mean of canal transportation followed by PTN, R, WO and PTU systems. At the straight portion, transportation for $R$ and TFA systems were similar $(P>.05)$, and these values were significantly lower than for WO, PTN and PTU $(P=.00)$. At the curved portion, TFA resulted in less canal transportation, followed by PTN, $R$, WO and PTU systems $(P=.00)$. Conclusions: TFA system produced less canal transportation than other systems tested during large apical preparations.
\end{abstract}

Keywords: Endodontics. Root canal preparation. Instrumentation.

Received for publication: October 3, 2016 Accepted: April 24, 2017

Correspondence to:

Prof. Dr. Emmanuel João Nogueira Leal Silva Department of Endodontics, School of Dentistry,

Grande Rio University (UNIGRANRIO)

Rua Herotides de Oliveira, 61/902, Icaraí Niterói - RJ - Brazil, ZIPCODE: 24230-230

Phone: (55) 2183575757

E-mail: nogueiraemmanuel@hotmail.com

\section{Introduction}

Root canal shaping is considered one of the most challenging tasks during endodontic treatment. Although several techniques were developed to minimize errors arising from root canal instrumentation ${ }^{1}$, accidents such as zips, ledges, root perforation and canal/apex transportation can occur, especially in narrow and curved canals ${ }^{2,3}$. Overall, nickel-titanium (NiTi) instruments have improved canal preparation procedures and reduced the odds of iatrogenic defects ${ }^{4,5}$. Briefly, NiTi files have improved mechanical canal preparation by offering better centering ability, less extrusion of debris and a reduced learning curve for the clinician ${ }^{4,5}$. Further developments of novel NiTibased root canal preparation systems have been primarily centered on modifications in instruments design, alloy and shaping movements. 
Canal preparation with reciprocating movement has been shown to reduce file fracture ${ }^{6-8}$. The reciprocation-based systems available on the market Reciproc (R) (VDW, Munich, Germany) and WaveOne (WO) (Dentsply Maillefer, Ballaigues, Switzerland)] allow single-file preparation for the entire root canal, thus requiring less time when compared to multi-file rotary systems. These files are made of a new NiTi alloy (M-wire), that in conjunction with the reciprocating kinematic, provided an increase in flexibility and an improved resistance to cyclic fatigue ${ }^{8}$.

Recently, the Twisted File Adaptive system (TFA) (SybronEndo; Orange, CA, USA) has been introduced onto the market. In theory, this system claims to maximize the advantages of using the reciprocation movement while downgrading possible disadvantages associated with this kinematic. The TFA system uses a patented unique motion technology, which automatically adapts the movement according to the instrumentation stress input to the file. According to the manufacturer, when stresses are imposed to the TFA instrument inside the canal, the motor performs a conventional clockwise movement, allowing better cutting efficiency and removal of debris. In contrast, during increased torsional stress, the movement automatically changes into a reciprocation mode. Furthermore, TFA files have three unique design features: a special surface conditioning, an R-phase heat treatment and a twisting of the metal ${ }^{9,10}$.

Recent scientific evidence shows that larger apical canal preparations promote more effective irrigation into the apical area, improved infection control and better quality of the root fillings ${ }^{11-13}$. However, limited data regarding canal transportation after larger apical preparations using these new NiTi systems are available. Thus, the aim of this study was to assess the ability of rotary [ProTaper Universal (PTU) (Dentsply Maillefer) and ProTaper Next (PTN) (Dentsply Maillefer)], reciprocating (R and WO) and adaptive (TFA) systems in maintaining the original profile in straight and curved parts of the canal after apical preparations up to size 40 . The null hypothesis tested was that there would be no differences in canal transportation values among the tested systems.

\section{Material and methods}

\section{Digital image acquisition}

A total of sixty Endo Training ISO 15 simulated curved canals in clear resin blocks (Dentsply Maillefer) with 2\% taper, $70^{\circ}$ angle of curvature, $10-\mathrm{mm}$ radius of curvature and $17-\mathrm{mm}$ length were assigned to five experimental groups and one control group $(n=10)$ according to the system used for canal preparation: PTU, PTN, R, WO and TFA. A circular base with a rectangular slot matching the resin block dimensions was inserted into the microscope base used to record the digital images (1005t Opticam stereomicroscope; Opticam, São Paulo, Brazil). After that, each specimen was positioned again in the slot, and color images were obtained and saved in TIFF format using a dedicated digital camera (CMOS 10 megapixels; Opticam). After the preparation procedures, new images were taken from each block following the same described protocol. In order to check the accuracy of the repositioning method, ten resin blocks were used as a control group where no canal preparation was performed. In this group, two stereoscopic images of each block were taken after consecutively inserting and removing each specimen from the silicon $\operatorname{slot}^{14}$.

\section{Canal preparation}

In all experimental groups, a $15 \mathrm{~K}$-file (Dentsply Maillefer) was used to scout the canal up to the working length (WL) in order to create an initial and standardized glide path. After that, each system was used in the following manner:

PTU. PTU instruments were used at $300 \mathrm{rpm}$ and $2 \mathrm{Ncm}$ torque (Silver Reciproc; VDW). The following sequence was used: SX file (19/0.04; $1 / 2$ of the WL), S1 file $(18 / 0.02 ; 2 / 3$ of the WL), S2 file (20/0.04; $2 / 3$ of the WL), F1 (20/0.07; full WL), F2 (25/0.08; full WL), F3 (30/0.09; full WL) and F4 (40/0.06; full WL) files.

PTN. PTN instruments were used at $300 \mathrm{rpm}$ and $2 \mathrm{Ncm}$ torque. The following sequence was used: X1 (17/0.04; full WL), X2 (25/0.06; full WL), X3 (30/0.07; full WL) and X4 (40/0.06; full $\mathrm{WL})$ files.

R. R40 (40/0.06) instruments were used at the pre-setting program (RECIPROC ALL) powered by a torque-controlled motor (Silver Reciproc). The instrument was gradually advanced in the root canal using pecking motion with a $3 \mathrm{~mm}$ amplitude limit. After 3 complete pecking movements, the instrument was removed from the simulated canal and were cleaned using a sponge.

WO. WO Large (40/0.08) files were used similarly to the $\mathrm{R}$ group, under WAVEONE ALL pre-setting program.

TFA. The instruments were used under TFA motion (Elements Adaptive motor; SybronEndo). The following sequence was used: SM1 (20/0.04; full WL), SM2 (25/0.06; full WL), SM3 (30/0.06; full WL), SM4 (35/0.06; full WL) and SM5 (40/0.04; full WL) files.

A single experienced operator performed all preparation procedures, and only new instruments were used. Apical patency was established with a $10 \mathrm{~K}$-file (Dentsply Maillefer) just beyond the WL between each preparation step. Canals were irrigated with $1.0 \mathrm{~mL}$ sterile water using 30G Max-i-Probe needle (Dentsply Rinn; Elgin, IL, USA) placed to a depth immediately short of binding. After the completion of each preparation, the canal was irrigated with $1.0 \mathrm{~mL}$ sterile water and post preparation images were acquired, as described previously.

\section{Image processing and analysis}

Filtering, registration, segmentation and extraction of attributes from the acquired images were performed using an open source software (FIJI) and its associated plugins ${ }^{15}$. Image processing and analysis was based on a previously published methodology ${ }^{14}$. In short, the images were first converted to 8-bit grayscale. Then, each pair of image (before and after canal preparation) was registered using the "Rigid Registration" plugin. An iterative polygon tracing tool was used as a threshold method to segment each canal (sound and instrumented) from the background. Canal boundaries were visually determined by the 
user aided by an automatic edge-segmentation algorithm. After tracing, a simple binarization scheme ( 0 for background, 255 for the defined polygon) was applied and, after that, a skeletonization algorithm was applied to the segmented images. This algorithm finds the centerlines (skeleton) in segmented images by applying binary thinning procedures (symmetrical erosion) ${ }^{16}$. The distance (in $\mathrm{mm}$ ) between each XY coordinate in the sound and in the instrumented skeleton images were calculated using the following formula:

$$
\sqrt{\left(x_{b}-x_{i}\right)^{2}+\left(y_{b}-y_{i}\right)^{2}}
$$

where $x_{b}$ and $y_{b}$ are coordinates for the sound canal and $x_{i}$ and $y_{i}$ are coordinates for the instrumented canal. Figure 1 shows images taken before and after preparation and the corresponding centerlines obtained after the analysis.

The transportation measurements were converted from pixels to millimeters $(\mathrm{mm})$ with the aid of a microscope magnification scale. After that, the transportation values were quantified for the complete canal or for two independent regions (straight and curved parts), as depicted in Figure 2.

\section{Statistical analysis}

Quantification of deviation by pixels resulted in a great number of data points (straight canal part $=21,960$ and curved canal part $=33,600)$. In this study, each pixel was considered as a unit for statistical analysis. Considering the data size, a bell-shaped distribution has been assumed, and a Univariate analysis of variance (two-way) procedure, with a significance level of $\alpha=5 \%$, has been selected considering root canal portion and instrumentation systems as independent variables and canal transportation (in mm) as the dependent. Tukey Honestly Significant Difference test was used for pair-wise comparisons.

\section{Results}

The control group showed no canal transportation, confirming the consistency and the reliability of the current methodology. As seen in Table 1, canal transportation was significantly influenced by the different instrumentation systems $(\mathrm{P}=.00)$. Compared with the straight part of the root canal, transportation values were increased at the curved canal parts $(\mathrm{P}=.00)$ for all instrumentation systems. When all canal extension was considered, TFA system induced the lowest mean of canal transportation followed by PTN, R, WO and PTU systems. However, a significant interaction between canal part and instrumentation system was found. At the straight portion, $\mathrm{R}$ and TFA systems produced similar transportation $(\mathrm{P}>.05)$, which was significantly lower than WO, PTN and PTU systems $(\mathrm{P}=.00)$; at the curved part, TFA system resulted in the lowest canal transportation followed by PTN, R, WO and PTU systems $(\mathrm{P}=.00)$. Figure 3 illustrates transportation values for each used system in each part of the simulated canal.
Table 1 - Canal transportation after large apical preparations using different instrumentation systems.

\begin{tabular}{lccc}
\hline System & Straight & Curved & All \\
\hline PTU $(n=10)$ & $0.087 \pm 0.149^{\mathrm{a}}$ & $0.199 \pm 0.244^{\mathrm{a}}$ & $0.160 \pm 0.221^{\mathrm{a}}$ \\
PTN $(\mathrm{n}=10)$ & $0.056 \pm 0.050^{\mathrm{b}}$ & $0.059 \pm 0.047^{\mathrm{c}}$ & $0.058 \pm 0.048^{\mathrm{d}}$ \\
R $(\mathrm{n}=10)$ & $0.025 \pm 0.016^{\mathrm{d}}$ & $0.111 \pm 0.065^{\mathrm{b}}$ & $0.080 \pm 0.067^{\mathrm{c}}$ \\
WO $(\mathrm{n}=10)$ & $0.040 \pm 0.034^{\mathrm{c}}$ & $0.110 \pm 0.067^{\mathrm{b}}$ & $0.085 \pm 0.066^{\mathrm{b}}$ \\
TFA $(\mathrm{n}=10)$ & $0.026 \pm 0.014^{\mathrm{d}}$ & $0.047 \pm 0.042^{\mathrm{d}}$ & $0.039 \pm 0.036^{\mathrm{e}}$ \\
\hline
\end{tabular}

Mean $(\mathrm{mm}) \pm$ Standard Deviation. Different lowercase letters indicate a significant difference $(P<0.05)$ in columns confirmed by Tukey Honestly Significant Difference for both straight and curved canal portions and for all canal extension.

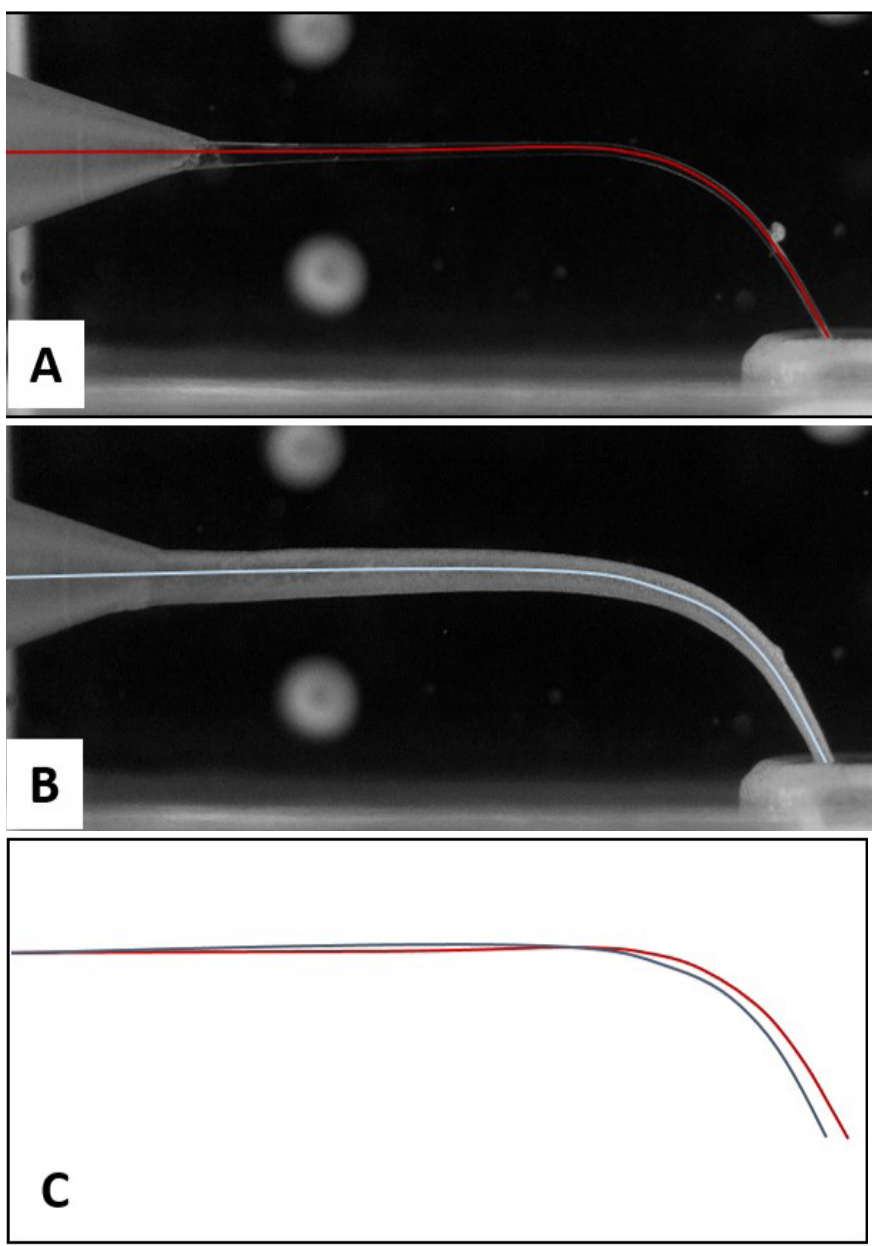

Fig. 1 - Image of a simulated canal block taken before (A) and after (B) preparation and corresponding centerlines obtained after the analysis. (C) Superposition of baseline and final centerlines showing that transportation occurred after instrumentation.

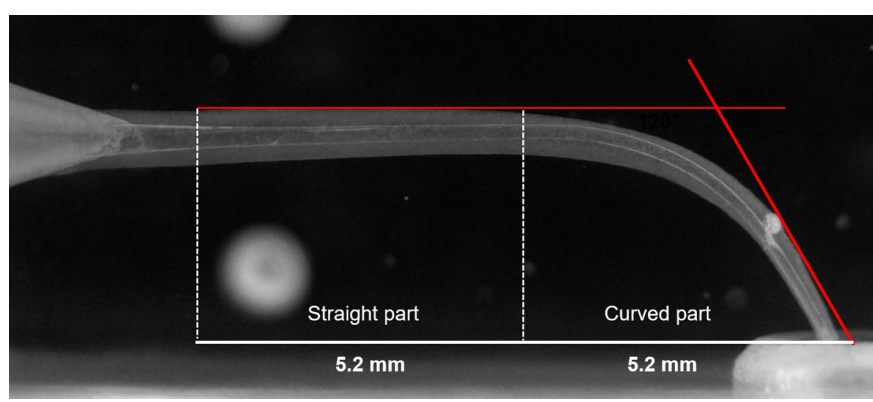

Fig. 2 - Determination of straight and curved parts of one simulated canal before and after instrumentation. 


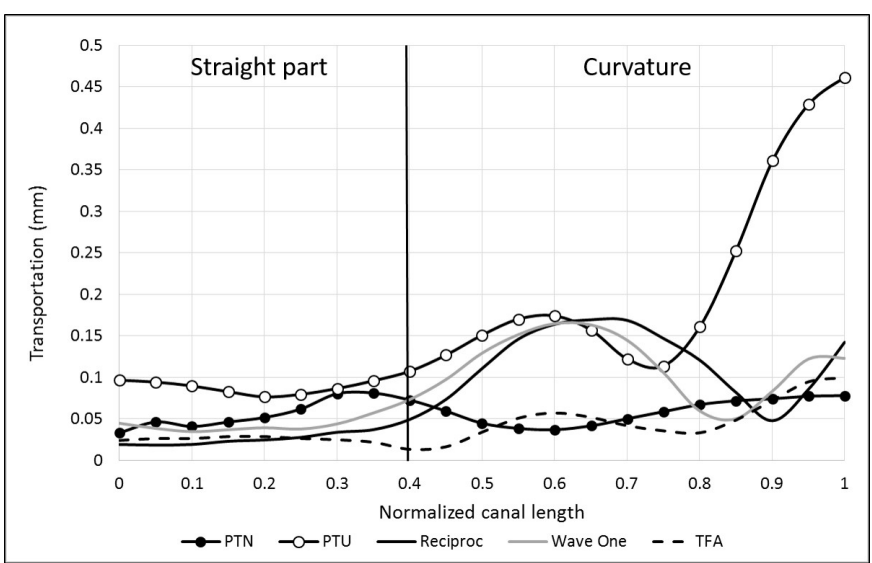

Fig. 3 - Transportation in the straight and curved portions for all instrumentation systems.

\section{Discussion}

Biomechanical preparation during root canal treatment is aimed to prevent or eliminate apical periodontitis, contributing to higher endodontic predictability ${ }^{17}$. Recent scientific evidence shows that larger apical preparations presents several advantages, such as increasing the irrigant solution volume at the apical third of the root canal system ${ }^{13,18}$, more debris elimination and a reduction of non-instrumented areas in the root canals ${ }^{19,20}$. Moreover, the increase in apical diameter is related to a reduction in bacterial population and improved canal filling procedures ${ }^{11-13}$. However, it is certainly not an easy clinical task to achieve a larger apical diameter, especially in curved, narrow and long canals. One major point of concern is associated with the higher incidence of mishaps such as canal transportation, which can occur during preparation of curved canals $^{2,3}$. Thus, it is relevant to assess the efficacy of root canal preparation instruments. Therefore, the current study compared the ability of PTU, PTN, R, WO and TFA systems in maintaining the original canal anatomy after large apical preparations.

The standardization of the experimental design is important during the evaluation of the shaping ability of different NiTi systems. However, due to the great number of confounding variables present in the experimental design of the commercially available instruments such as the manufacturing process, the number of files and kinematics, it is not always possible to isolate the influence of each variable on the obtained results.

Overall, the findings of the present study showed that the TFA system presented lower canal transportation than the other systems tested. The null hypothesis was then rejected. Previous studies have already shown that the TFA system induced lower canal transportation and produced a better centering ability when compared to rotary ${ }^{14}$ and reciprocating systems ${ }^{10,21}$. This result may be explained by the TFA system unique design features (special surface conditioning, R-phase heat treatment and twisting of the metal) $)^{9,10}$ associated with its lower taper (0.04). Regarding the adaptive motion, Silva et al. ${ }^{14}$ (2015) evaluated canal transportation using Twisted File system both in adaptive and in rotary motions and concluded that the latter produced overall lower canal transportation ${ }^{10}$. Therefore, this new kinematics cannot be considered as the solely factor influencing the good results of TFA system herein. On the other hand, the PTU system exhibited the worst results, showing higher canal transportation, which are in agreement with previous studies ${ }^{5,14}$. Some aspects might give some rationale to support these results. First, the PTU system used seven instruments to prepare the canals. In addition, it is conceived that the PTU system has a tendency to straighten curved canals causing transportation toward the furcation at the middle-coronal thirds and toward the outer aspect of the curvature at the apical third ${ }^{22}$.

Although R and WO systems have some similarities, such as the reciprocating motion and the M-wire NiTi alloy, $\mathrm{R}$ system showed less transportation in the straight portion and when all canal was considered. These results may be explained by differences in the cross-sectional design: the larger cross-sectional area of W system influences the bending resistance of the instrument, making it less flexible and increasing the straightening tend in curved canals ${ }^{23}$. The results obtained by the PTN system may be explained by the use of a progressive tapers on a single file and the unique offset mass of rotation. This design serves to minimize the contact between a file and dentine, decreasing dangerous taper lock, screw effect and root canal transportation.

Simulated curved canals in clear resin blocks were used in the current study. This method has been previously validated in order to evaluate the centering ability and canal transportation provided by endodontic instruments $s^{3,14}$. In addition, it is particularly attractive due to the possibility of standardizing the full canal anatomy. Nevertheless, the use of resin blocks has a few disadvantages such as micro-hardness differences between the resin material and the root dentin, and the possible side effects created by heat generated during preparation procedures, which may soften the resin, leading to binding of the cutting blades and enhancing the chance of instrument fracture ${ }^{24}$. Thus, care should be taken before extrapolating these results directly to a clinical situation.

The present investigation used a recent described methodology to study transportation in simulated curved canals by confronting images before and after canal preparation ${ }^{14}$. This procedure has the potential to reduce the bias related to the subjective operatorbased image superimposition schemes and evaluation of canal transportation, once it is almost not dependent on user input and also provides information from the whole canal length, and not only from selected slices. Although the bi-dimensional approach can be considered a limitation of this method, it is of outmost importance to state that current three-dimensional-based techniques used to assess canal transportation have not yet provided fully quantitative volumetric data ${ }^{10,25}$, which again results in the evaluation of limited slices and manual selection of gravity center points.

\section{Conclusions}

Under the conditions of this study, it can be concluded that TFA system produced less canal transportation than the other systems tested during large apical preparations.

\section{References}

1. Roane JB, Sabala CL, Duncanson JG. The balanced force concept for instrumentation of curved canals. J Endod. 1985 May;11(5):203-11. 
2. Peters AO, Peters IC. Cleaning and shaping of the root canal system. In: Cohen S, Hargreaves MK, editors. Pathways of the Pulp. 9. ed. Saint Louis: Mosby Inc; 2006. p. 290-357.

3. Weine FS, Kelly RF, Lio PJ. The effect of preparation procedures on original canal shape and on apical foramen shape. J Endod. 1975 Aug;1(8):255-62.

4. Bergmans L, Van Cleynenbreugel J, Wevers M, Lambrechts P. Mechanical root canal preparation with NiTi rotary instruments: rationale performance and safety - status report for the American Journal of Dentistry. Am J Dent. 2001 Oct;14(5):324-33.

5. Gergi R, Rjeily JA, Sader J, Naaman A. Comparison of canal transportation and centering ability of Twisted Files, Pathfile-ProTaper system, and stainless steel hand K-files by using computed tomography. J Endod. 2010 May;36(5):904-7. doi: 10.1016/j.joen.2009.12.038.

6. De-Deus G, Moreira EJ, Lopes HP, Elias CN. Extended cyclic fatigue life of F2 ProTaper instruments used in reciprocating movement. Int Endod J. 2010 Dec;43(12):1063-8.

7. Kiefner $P, B$ an $M$, De-Deus $G$. Is the reciprocating movement per se able to improve the cyclic fatigue resistance of instruments? Int Endod J. 2014 May;47(5):430-6. doi: 10.1111/iej.12166.

8. Gambarini G, Rubini AG, Al Sudani D, Gergi R, Culla A, De Angelis F, et al. Influence of different angles of reciprocation on the cyclic fatigue of nickel-titanium endodontic instruments. J Endod. 2012 Oct;38(10):140811. doi: 10.1016/j.joen.2012.05.019.

9. Gambarini G, Gergi R, Naaman A, Osta N, Al Sudani D. Cyclic fatigue of twisted file rotary NiTi instruments used in reciprocating motion. Int Endod J. 2012 Sep;45(9):802-6. doi: 10.1111/j.1365-2591.2012.02036.x.

10. Gergi R, Osta N, Bourbouze G, Zgheib C, Arbab-Chirani R, Naaman A. Effects of three nickel titanium instrument systems on root canal geometry assessed by micro-computed tomography. Int Endod J. 2015 Feb;48(2):162-70. doi: 10.1111/iej.12296.

11. van der Sluis LW, Shemesh H, Wu MK, Wesselink PR. An evaluation of the influence of passive ultrasonic irrigation on the seal of root canal fillings. Int Endod J. 2007 May;40(5):356-61.

12. ElAyouti A, Kiefner P, Hecker H, Chu A, Löst C, Weiger R. Homogeneity and adaptation of endodontic fillings in root canals with enlarged apical preparation. Oral Surg Oral Med Oral Pathol Oral Radiol Endod. 2009 Sep;108(3):e141-6. doi: 10.1016/j.tripleo.2009.04.022.

13. Brunson M, Heilborn C, Johnson DJ, Cohenca N. Effect of apical preparation size and preparation taper on irrigant volume delivered by using negative pressure irrigation system. J Endod. 2010 Apr;36(4):721-4. doi: 10.1016/j.joen.2009.11.028.

14. Silva EJ, Tameirão MD, Belladonna FG, Neves AA, Souza EM, DeDeus G. Quantitative transportation assessment in simulated curved canals prepared with an Adaptive Movement System. J Endod. 2015 Jul;41(7):1125-9. doi: 10.1016/j.joen.2015.02.028.

15. Schneider CA, Rasband WS, Eliceiri KW. NIH Image to Image J: 25 years of image analysis. Nature Methods. 2012 Jul;9(7):671-5.

16. Lee TC, Kashyap RL, Chu CN. Building skeleton models via 3-D medial surface/axis thinning algorithms. Comput Vis Graph Image Process. 1994;56:462-78.

17. Schilder H. Cleaning and shaping the root canal. Dent Clin North Am. 1974 Apr;18(2):269-96.

18. Boutsioukis C, Gogos C, Verhaagen B, Versluis M, Kastrinakis E, Van der Sluis LW. The effect of root canal taper on the irrigant flow: evaluation using an unsteady computational fluid dynamics model. Int Endod J. 2010 Oct;43(10):909-16. doi: 10.1111/j.1365-2591.2010.01767.x.

19. Fornari VJ, Silva-Sousa YT, Vanni JR, Pécora JD, Versiani MA, SousaNeto MD. Histological evaluation of the effectiveness of increased apical enlargement for cleaning the apical third of curved canals. Int Endod J. 2010 Nov;43(11):988-94. doi: 10.1111/j.1365-2591.2010.01724.x.

20. De-Deus G, Marins J, Silva EJ, Souza E, Belladonna FG, Reis C, et al. Accumulated hard tissue debris produced during reciprocating and rotary nickel-titanium canal preparation. J Endod. 2015 May;41(5):676-81. doi: 10.1016/j.joen.2014.11.028.

21. Ordinola-Zapata R, Bramante CM, Duarte MA, Cavenago BC, Jaramillo $D$, Versiani MA. Shaping ability of Reciproc and TF adaptive systems in severely curved canals of rapid microCT-based prototyping molar replicas. J Appl Oral Sci. 2014 Nov-Dec;22(6):509-15. doi: 10.1590/1678775720130705.

22. Bürklein $\mathrm{S}$, Schäfer E. Critical evaluation of root canal transportation by instrumentation. Endod Topics. 2013;29:110-24.

23. De-Deus G, Vieira VTL, Silva EJNL, Lopes HP, Elias CN, Moreira EJ. Bending resistance and dynamic and static cyclic fatigue life of Reciproc and WaveOne large instruments. J Endod. 2014 Apr;40(4):575-9. doi: 10.1016/j.joen.2013.10.013.

24. Yoo YS, Cho YB. A comparison of the shaping ability of reciprocating NiTi instruments in simulated curved canals. Restor Dent Endod. 2012 Nov;37(4):220-7. doi: 10.5395/rde.2012.37.4.220.

25. Freire LG, Gavini G, Cunha RS, Santos MD. Assessing apical transportation in curved canals: comparison between cross-sections and micro-computed tomography. Braz Oral Res. 2012 May-Jun;26(3):222-7. 